\title{
Morfoanatomia e ontogênese da sâmara de Pterocarpus violaceus Vogel (Fabaceae: Faboideae) ${ }^{1}$
}

\author{
ADRIANA TIEMI NAKAMURA² e DENISE MARIA TROMBERT OLIVEIRA ${ }^{2,3}$
}

(recebido: 19 de setembro de 2003; aceito: 17 de fevereiro de 2005)

\begin{abstract}
Morphology, anatomy and ontogeny of Pterocarpus violaceus Vogel (Fabaceae: Faboideae) samara). Morphological, anatomical and developmental descriptions of $P$. violaceus fruits and seeds were made in order to verify the origin of the pericarpic wing and the occurrence of polyembryonic seeds, previously described for other Dalbergieae genera. The fruit is a circular, glabrous samara. Seeds show some typical characters of the Faboideae specially in the hilar region. We describe six different fruit developmental stages. The pericarpic wing originates from the expansion of the ovary wall; the pericarp grows dorsiventrally, apically and basally, producing a flattened structure. In all material analysed, we do not find polyembryonic seeds. We also conclude that the pericarp of $P$. violaceus is unusual because of the fusion of its ventral vascular bundles, a feature that is considered phylogenetically derived for the group.
\end{abstract}

Key words - anatomy, fruit, morphology, Pterocarpus violaceus, seed

RESUMO - (Morfoanatomia e ontogênese da sâmara de Pterocarpus violaceus Vogel (Fabaceae: Faboideae)). Neste trabalho, os frutos e sementes de $P$. violaceus foram descritos morfoanatômica e ontogeneticamente, visando a verificar a origem da ala pericárpica e checar a ocorrência de poliembrionia, previamente descrita para outros gêneros da tribo Dalbergieae. Observou-se que o fruto é uma sâmara circular, de aspecto glabro e que a semente possui alguns caracteres típicos de Faboideae, especialmente os relacionados ao hilo. Foram caracterizados atomicamente seis estádios de desenvolvimento. A ala pericárpica origina-se da parede ovariana, por extensões dorso-ventral, apical e basal, produzindo uma estrutura achatada. Não foi possível encontrar poliembrionia, mesmo analisando-se grande número de sementes. Pôde-se também concluir que, no que se refere à estrutura do fruto, $P$. violaceus é filogeneticamente derivada com relação às outras espécies de Dalbergieae já registradas na literatura, devido à presença de fusão dos feixes ventrais do carpelo.

Palavras-chave - anatomia, fruto, morfologia, Pterocarpus violaceus, semente

\section{Introdução}

Informações a respeito dos órgãos reprodutivos de espécies de leguminosas vêm sendo utilizadas com grande eficiência para finalidades taxonômicas (Gunn 1984, Lima 1989-1990). Dessa maneira, é cada vez maior a procura por informações a respeito dos frutos e sementes das Fabaceae, de forma a complementar aquelas provenientes dos órgãos vegetativos. Quando o interesse passa para o campo filogenético, a análise dos órgãos reprodutivos torna-se ainda mais imprescindível.

É importante destacar que a morfologia dos frutos e sementes exibe usualmente pequena plasticidade fenotípica. Os caracteres embriológicos, por sua vez,

1. Parte da monografia de bacharelado em Ciências Biológicas de A.T. Nakamura, Unesp - Botucatu.

2. Universidade Estadual Paulista - Unesp, Instituto de Biociências, Departamento de Botânica, Caixa Postal 510, 18618-000 Botucatu, SP, Brasil.

3. Autor para correspondência: denise@ibb.unesp.br são usualmente constantes dentro de um gênero, funcionando como significativos indicadores da afinidade taxonômica (von Teichman \& van Wyk 1991). Esses mesmos autores afirmaram ainda que existem poucos estudos descritivos e ontogenéticos da estrutura seminal, o que torna difícil especular a respeito das tendências evolutivas que afetaram a semente.

A maior das três subfamílias de Fabaceae é Faboideae, compreendendo cerca de 440 gêneros e 12.000 espécies (Polhill 1981b). Muitas dessas espécies ocorrem nas regiões tropicais, estando significativa parte das tribos Aeschynomeneae, Dalbergieae e Sophoreae centrada na América Latina (Raven \& Polhill 1981).

Dentre as Faboideae, a tribo Dalbergieae tem sido considerada um dos grupos ancestrais (Polhill et al. 1981), mostrando grande variação tipológica nos frutos. Observam-se frutos drupáceos, frutos fibrosos e variadas formas de pericarpo alado, incluindo sâmaras típicas e frutos samaróides. Pelas observações já registradas na literatura e referidas por Polhill (1981a), essa tribo exibe grande variação no modo de formação da ala pericárpica, que pode ter as seguintes origens: expansão do pedicelo ou do estilete, atenuação da 
margem do fruto ou fusão e achatamento das valvas. Polhill (1981a) enfatizou que os frutos das espécies dessa tribo são sempre indeiscentes, formando cavidades seminais em geral monospérmicas, delimitadas e protegidas pelo endocarpo lenhoso.

Outros estudos confirmaram as proposições supracitadas para os frutos de Dalbergieae: Lima (1989-1990) citou somente frutos indeiscentes para a tribo, referindo sâmaras (incluindo aquelas de núcleo seminífero bem delimitado e os frutos samaróides) para 13 gêneros, ocorrendo ainda núculas e drupas. Barroso et al. (1999) afirmaram que sâmaras são encontradas principalmente entre os componentes dessa tribo.

A morfologia das sâmaras, núculas e drupas é muito importante para caracterizar alguns gêneros das tribos Dalbergieae, Dipterigeae e Sophoreae. Esses caracteres geralmente se sobrepõem às características florais, reforçando mais ainda o seu uso (Barroso et al. 1999). A morfologia da ala é tão importante em Dalbergieae que tem sido utilizada para distinguir três gêneros da tribo, cuja morfologia floral é praticamente idêntica: Platypodium Vogel, Pterocarpus Jacq. e Tipuana (Benth.) Benth. (Lima 1989-1990). Além disso, a posição da ala e a estrutura do pericarpo são caracteres freqüentemente usados na delimitação de gêneros da tribo Sophoreae e Dalbergieae (Barroso et al. 1999).

Para o presente trabalho, selecionou-se Pterocarpus violaceus Vogel (aldrago ou pau-vidro), espécie que ocorre do sul da Bahia e Minas Gerais até o Paraná, na floresta pluvial da encosta Atlântica. É uma árvore ornamental de fácil multiplicação, sendo componente indispensável nos reflorestamentos de áreas degradadas de preservação permanente. Floresce de outubro a dezembro e os frutos e as sementes amadurecem no período de maio a julho (Lorenzi 1992).

Os objetivos deste trabalho foram descrever morfoanatômica e ontogeneticamente os frutos e sementes de $P$. violaceus, buscando verificar a origem da ala pericárpica e checar a ocorrência de poliembrionia, fornecendo subsídios para trabalhos taxonômicos e filogenéticos envolvendo a tribo Dalbergieae.

\section{Material e métodos}

Foram utilizados primórdios e botões florais, flores em antese e pós-antese, frutos jovens em diversas fases de desenvolvimento e frutos maduros de P. violaceus Vogel, coletados de indivíduos cultivados na Fazenda Lageado da Unesp, Câmpus de Botucatu, São Paulo, Brasil. Pequenos ramos foram coletados, herborizados e depositados no Herbário "Irina D. Gemtchujnikov" (BOTU) do Departamento de Botânica, Unesp, Câmpus de Botucatu, como documento taxonômico.

Os estudos morfoanatômicos foram realizados em material fresco e material fixado em FAA 50 (Johansen 1940) ou na mistura de Karnovsky (Karnovsky 1965), ambos conservados em álcool etílico a 70\%. Após desidratação em série etílica, o material foi incluído em metacrilato e seccionado com cerca de $10 \mu \mathrm{m}$ de espessura, obtendo-se séries longitudinais e transversais. As seções obtidas foram coradas com azul de toluidina (O'Brien et al. 1964) e montadas em Permount.

Foram realizados testes microquímicos usuais, como vermelho de rutênio, visando à detecção de polissacarídeos e pectinas (Jensen 1962); floroglucinol em meio ácido, para identificar lignina (Sass 1951); Sudan IV, para a localização de substâncias lipofílicas; lugol, para detectar amido; e cloreto férrico, para verificar a ocorrência de compostos fenólicos (Johansen 1940).

Frutos e sementes maduros foram detalhadamente observados a olho nu e sob estereomiscroscópio, produzindo-se ilustrações em câmara clara.

O laminário preparado foi analisado em microscópio fotônico, sendo os detalhes apresentados em fotomicrografias obtidas em fotomicroscópio Zeiss. Para todas as ilustrações, foram preparadas escalas nas condições ópticas adequadas.

\section{Resultados}

Estádio I (figuras 1-5) - O estádio inicial do desenvolvimento dos frutos e sementes é representado pelo ovário e óvulos contidos nos botões florais (figuras 1-5). O ovário é unilocular e levemente estipitado (figura 2), possuindo seção transversal mediana elíptica, ligeiramente alargada na face ventral e mais aguda na face dorsal (figura 1).

A epiderme externa do ovário é unisseriada, apresentando numerosos tricomas tectores pluricelulares, de paredes espessadas (figuras 4-5). O mesofilo ovariano possui a camada subepidérmica constituída por células cubóides de conteúdo fenólico (figuras 3-5), sendo as demais parenquimáticas e isodiamétricas. Vascularizando o ovário, observam-se um feixe dorsal e um ventral, este com pequeno grau de diferenciação. São observados também alguns cordões procambiais imersos no mesofilo na região lateral do ovário. A epiderme interna do ovário é unisseriada, revestida internamente por cutícula delgada (figura 3-4). Na região de placentação, a epiderme torna-se papilosa.

O ovário contém cinco a seis óvulos campilótropos, bitegumentados e crassinucelados. Nessa fase, os tegumentos estão em formação e ainda não definem a micrópila (figura 3). 


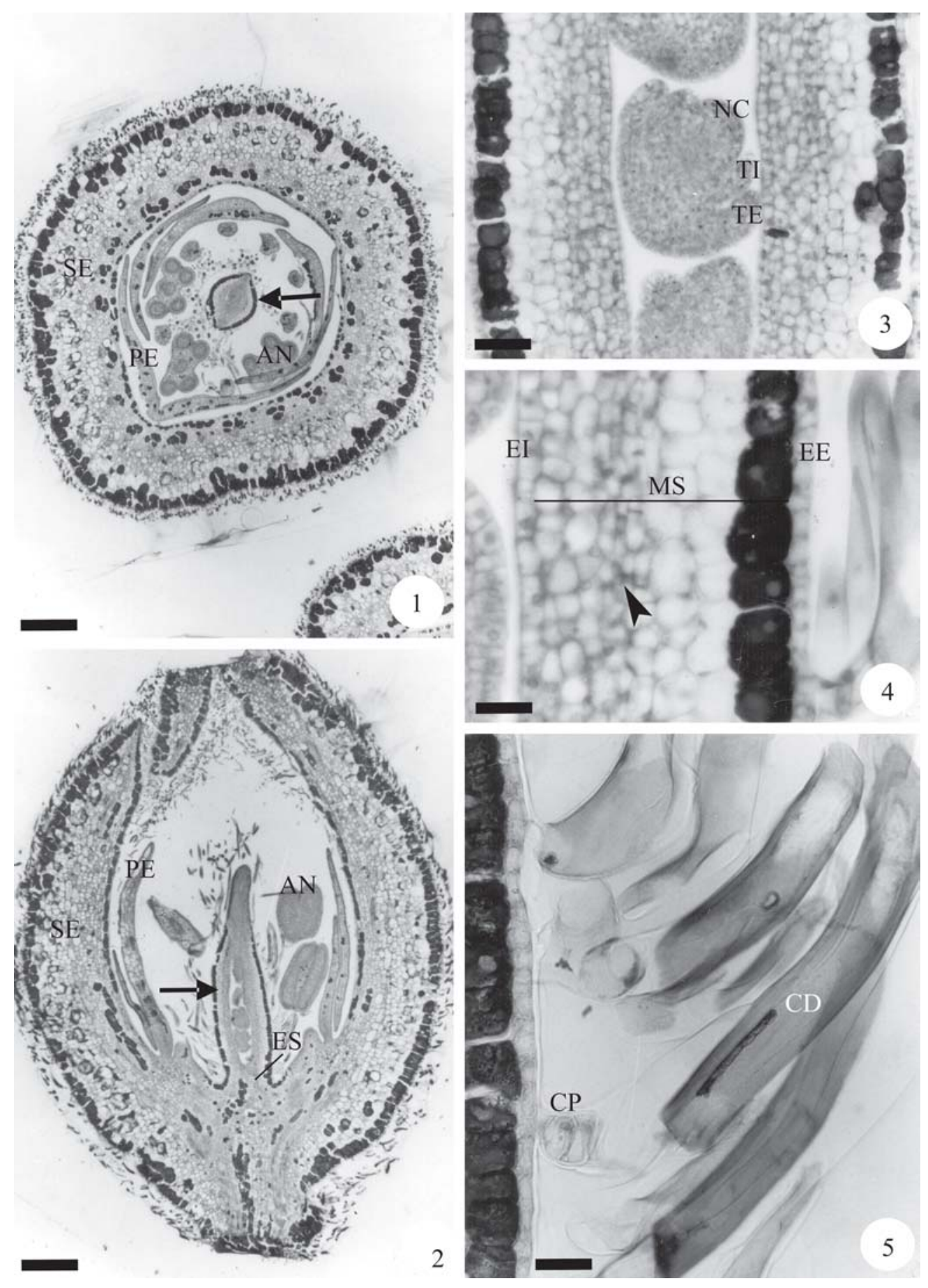

Figuras 1-5. Pterocarpus violaceus. Estádio I. 1-2. Vista geral do botão floral em seção transversal e longitudinal, respectivamente (seta indica ovário). 3. Seção longitudinal do primórdio de óvulo com nucelo, tegumento externo e interno em formação. 4. Detalhe da parede ovariana, em seção longitudinal. 5. Seção longitudinal da epiderme externa do ovário, mostrando tricomas tectores pluricelulares. $(\mathrm{AN}=$ antera; $\mathrm{CD}=$ célula distal do tricoma; $\mathrm{CP}=$ célula proximal do tricoma; $\mathrm{EE}=$ epiderme externa do ovário; $\mathrm{EI}=$ epiderme interna do ovário; $\mathrm{ES}=$ estipe; $\mathrm{MS}=$ mesofilo ovariano; $\mathrm{NC}=$ nucelo; $\mathrm{PE}$ = pétala; $\mathrm{SE}=$ sépala; $\mathrm{TE}=$ tegumento externo; $\mathrm{TI}=$ tegumento interno). Barra $=400 \mu \mathrm{m}(1-2), 50 \mu \mathrm{m}(3), 25 \mu \mathrm{m}(4-5)$.

Figures 1-5. Pterocarpus violaceus. Stage I. 1-2. General view of floral bud in TS and LS respectively (arrow indicates ovary). 3. LS of young ovule with nucellus and outer and innner integument in formation. 4. Detail of the ovary wall in LS. 5. LS of outer epidermis of the ovary with non-glandular pluricellular trichome. $(\mathrm{AN}=$ anther; $\mathrm{CD}=$ distal cell of trichome; $\mathrm{CP}=$ proximal cell of trichome; $\mathrm{EE}$ = ovary outer epidermis; $\mathrm{EI}$ = ovary inner epidermis; $\mathrm{ES}=$ stipe; $\mathrm{MS}=$ mesophyll; $\mathrm{NC}=$ nucellus; $\mathrm{PE}=$ petal; $\mathrm{SE}$ $=$ sepal; $\mathrm{TE}=$ outer integument; $\mathrm{TI}=$ inner integument). $\mathrm{Bar}=400 \mu \mathrm{m}(1-2), 50 \mu \mathrm{m}$ (3), $25 \mu \mathrm{m}$ (4-5). 
Estádio II (figuras 6-9) - Compreende a fase em que se observa intensa atividade meristemática da parede ovariana e do óvulo, embora este não tenha seu tamanho muito alterado. É representado pelo ovário da flor em antese e pós-antese. O ovário torna-se um pouco mais alongado em seção transversal, devido ao maior desenvolvimento das regiões dorsal e ventral.

A epiderme externa do ovário (figuras 6-8) mantém-se similar ao descrito no estádio I. Na região ventral, observa-se pequena invaginação na margem, indicando a região sutural (figura 7).

A camada fenólica do mesofilo multiplica-se apenas anticlinalmente e idioblastos fenólicos encontram-se imersos no tecido parenquimático (figuras 6-8). Há diferenciação dos feixes dorsal (figura 6), laterais (figura 8) e ventral (figura 7), sendo esse último mais amplo que os demais.

Durante a ontogênese, há formação de falsos septos na cavidade ovariana (figura 9), a partir de proliferação de células do endo e mesocarpo, persistindo até o fruto maduro.

A epiderme interna divide-se periclinalmente, ao redor da cavidade seminal e, anticlinalmente, constituindo projeções laterais (figura 6), que mais tarde formarão o endocarpo fibroso da ala circular.

O óvulo é campilótropo (anti-rafe bem mais longa que a rafe), possui a micrópila delimitada pelos dois tegumentos, sendo disposta em zigue-zague. Internamente, o saco embrionário se desenvolve, após a fecundação, consumindo parte do nucelo (figura 9). Durante essa fase, ocorre a fecundação e dá-se o início da embriogênese e a produção do endosperma. Ainda assim, o tamanho do óvulo após a fecundação é pouco alterado.

Estádio III (figura 10) - Fase caracterizada pelo intenso alongamento celular pericárpico, acompanhado de pequeno crescimento seminal. $\mathrm{O}$ alongamento pericárpico é dado principalmente pelo desenvolvimento da ala circular, o fruto se torna mais alongado, perdendo sua seção transversal elíptica e tornando-se achatado. Ao final dessa fase, o tamanho e o formato do fruto estão definidos.

No exocarpo, ocorre a diminuição da densidade de tricomas no final deste estádio. Além de não se diferenciarem novos tricomas durante a ontogênese, alguns se desprendem por ruptura das células proximais, cujas paredes celulares são delgadas e de natureza péctica.

No mesocarpo, os idioblastos secretores fundem-se entre si (figuras 10-12) e as células parenquimáticas aumentam seu volume. Alguns feixes vasculares laterais se diferenciam.

O endocarpo apresenta duas regiões bastante distintas: o endocarpo externo, com grande alongamento celular, especialmente na região da ala, e o endocarpo interno, parenquimático e que preenche grande parte da cavidade seminal (figuras 10-13).

A semente jovem possui testa com epiderme externa unisseriada, de conteúdo fenólico. A mesotesta é composta por células parenquimáticas, de paredes delgadas e a endotesta é indiferenciada. O tegumento interno sofre compressão, exibindo células de formato alongado pouco diferenciadas. O nucelo fica representado apenas por resíduos celulares (figura 10). $\mathrm{O}$ endosperma é nuclear e abundante nessa fase. Ele inicia a celularização periférica e vai sendo consumido pelo embrião que está em processo de diferenciação. Estádio IV (figuras 11-15) - É a fase caracterizada pelo amadurecimento do pericarpo, enquanto a semente se mantém bastante jovem. A principal mudança que ocorre nessa fase é a lignificação pericárpica (figuras 11-13). Os frutos maduros têm contorno circular e de seção transversal elíptica bem achatada.

No exocarpo, há abscisão de grande parte dos tricomas. Devido a esse fato e ao grande alongamento ocorrido no estádio III, o exocarpo exibe aspecto glabro (figuras 11-12).

No mesocarpo, ocorre lignificação das fibras dos feixes vasculares e também de alguns pequenos blocos de fibras, dispostos aleatoriamente nesta região (figura 11).

O endocarpo completa a diferenciação de suas duas regiões. O endocarpo externo é composto por fibras bem lignificadas em disposições variadas (figuras 12-13); esta região do endocarpo estende-se por todo o fruto, desde o núcleo seminífero até a ala. Numerosos cristais prismáticos de oxalato de cálcio podem ser observados constituindo fileiras que acompanham o endocarpo externo, tanto interna quanto externamente; outros cristais podem ser encontrados aleatoriamente entre as fibras que compõem esta região. $\mathrm{O}$ endocarpo interno, contudo, é observado apenas na região do núcleo seminífero (figuras 11, 13). É composto por células de arranjo frouxo e formato irregular (figura 13). Algumas dessas células possuem conteúdo resinífero, cuja composição química abrange compostos fenólicos, lipídios e alcalóides. Ao final deste estágio, a maior parte do pericarpo está representada pelo endocarpo.

A semente possui a exotesta paliçádica, de conteúdo fenólico (figuras 14-15). Na região do hilo, a epiderme forma uma dupla paliçada e pode-se observar também a barra de traqueídes em diferenciação 

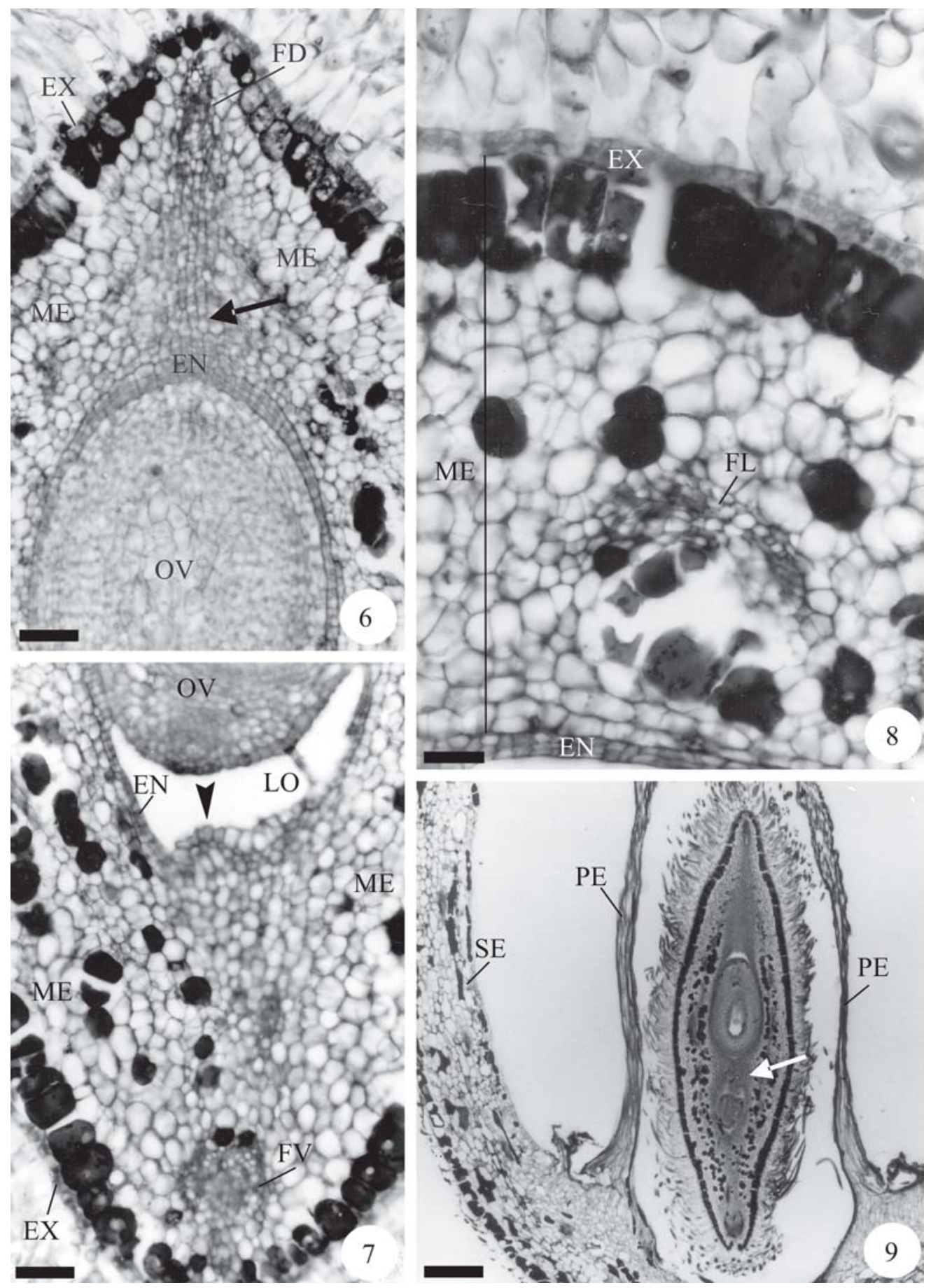

Figuras 6-9. Pterocarpus violaceus. Estádio II. Seções transversais do ovário da flor pós-antese, exceto 9, que é longitudinal. 6. Região dorsal (seta indica o tecido precursor do endocarpo fibroso na ala). 7. Região ventral (ponta de seta indica células papilosas). 8. Detalhe do pericarpo jovem com endocarpo em divisão. 9. Vista geral do fruto jovem, ainda protegido por sépalas e resíduos de pétalas, mostrando a formação do falso septo (seta). (EN = endocarpo; $E X=$ exocarpo; $F D=$ feixe dorsal; $\mathrm{FL}=$ feixe lateral; $\mathrm{FV}=$ feixe ventral $; \mathrm{LO}=$ lóculo; $\mathrm{ME}=$ mesocarpo; $\mathrm{PE}=$ pétala; $\mathrm{OV}=$ óvulo; $\mathrm{SE}=$ sépala). $\mathrm{Barra}=50 \mu \mathrm{m}(6-7)$, $25 \mu \mathrm{m}(8), 400 \mu \mathrm{m}(9)$.

Figures 6-9. Pterocarpus violaceus. Stage II. Ovary at the post-anthesis stage in TS (9, LS). 6. Dorsal region (arrow indicates the precursory tissue of the fibrous endocarp in the wing). 7. Ventral region (arrowhead indicates papillae). 8. Detail of young pericarp with inner epidermis in division. 9. General view of young fruit surrounded by sepals and petals; note the false septum (arrow). $(\mathrm{EN}=$ endocarp; $\mathrm{EX}=$ exocarp; $\mathrm{FD}=$ dorsal bundle; $\mathrm{FL}=$ lateral bundle; $\mathrm{FV}=$ ventral bundle; $\mathrm{LO}=$ locule; $\mathrm{ME}=$ mesocarp; $\mathrm{PE}=$ petal; $\mathrm{OV}=$ ovule; $\mathrm{SE}=$ sepal). $\mathrm{Bar}=50 \mu \mathrm{m}(6-7), 25 \mu \mathrm{m}(8), 400 \mu \mathrm{m}(9)$. 

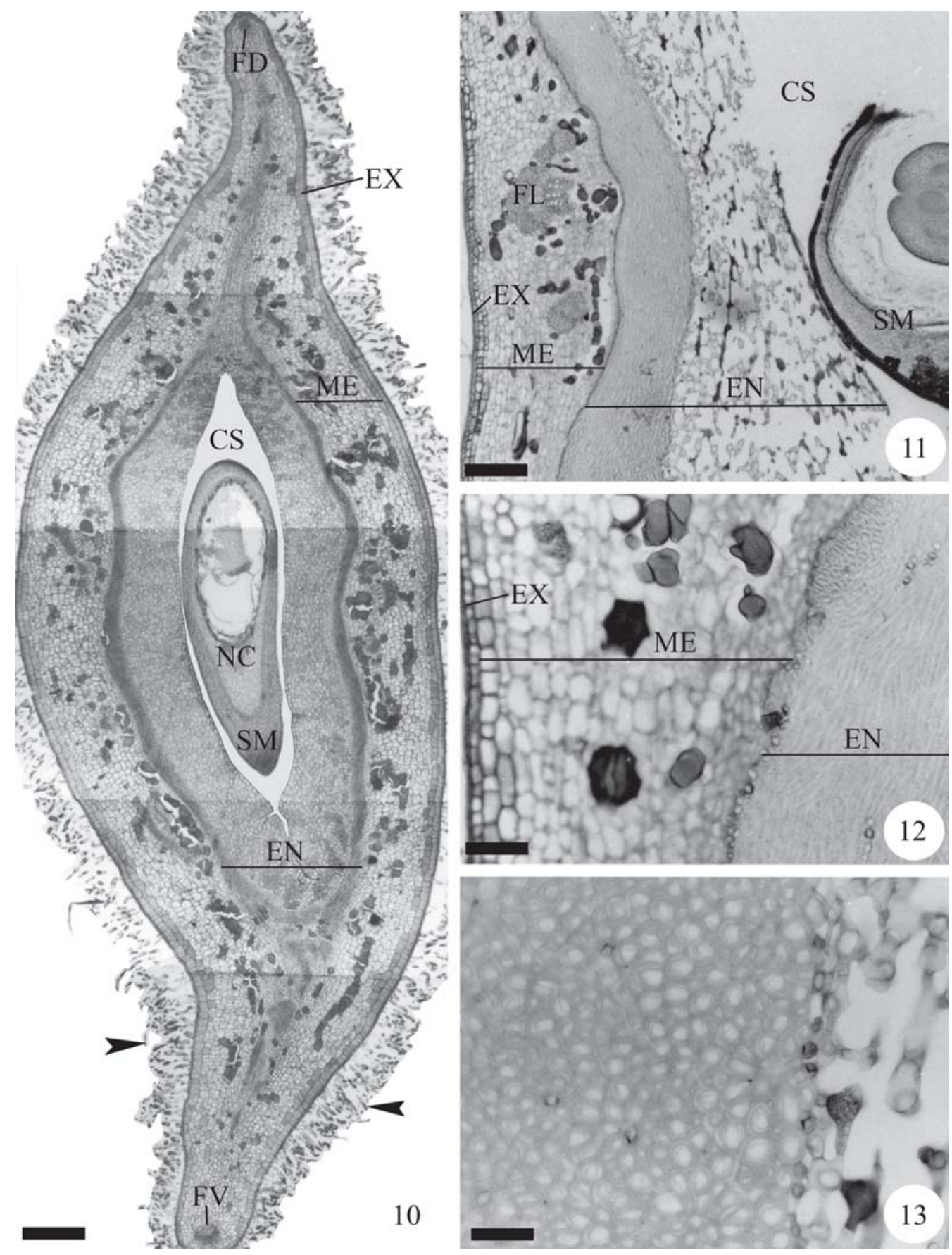

Figuras 10-13. Pterocarpus violaceus. Seções transversais. 10. Estádio III. Fruto jovem mostrando alongamento celular pericárpico; as pontas de seta indicam tricomes tectores. 11-13. Estádio IV. 11. Vista geral do pericarpo na região do núcleo seminífero. 12. Detalhe do exocarpo, mesocarpo e endocarpo externo lignificado. 13. Detalhe do endocarpo externo e interno, este último com células braciformes. $(\mathrm{CS}=$ cavidade seminal; $\mathrm{EN}=$ endocarpo; $\mathrm{EX}=$ exocarpo; $\mathrm{FD}=$ feixe dorsal; $\mathrm{FL}=$ feixe lateral; $\mathrm{FV}=$ feixe ventral; $\mathrm{ME}=$ mesocarpo; $\mathrm{NC}=$ nucelo; $\mathrm{SM}=$ semente). $\mathrm{Barra}=200 \mu \mathrm{m}(10), 400 \mu \mathrm{m}(11), 100 \mu \mathrm{m}(12), 25 \mu \mathrm{m}(13)$.

Figures 10-13. Pterocarpus violaceus. TS. Stage III. 10. Young fruit showing pericarp enlongation; the arrowhead indicate nonglandular trichomes. 11-13. Stage IV. 11. General view of the pericarp at the seed chamber region. 12. Detail of exocarp, mesocarp and outer fibrous endocarp. 13. Detail of inner and outer endocarp, with armed cells. (CS $=$ seed chamber; EN = endocarp; $\mathrm{EX}=$ exocarp; FD = dorsal bundle; FL = lateral bundle; FV = ventral bundle; $\mathrm{ME}=$ mesocarp; $\mathrm{NC}=$ nucellus; $\mathrm{SM}=$ seed). $\operatorname{Bar}=200 \mu \mathrm{m}(10), 400 \mu \mathrm{m}(11), 100 \mu \mathrm{m}(12), 25 \mu \mathrm{m}(13)$. 
(figura 14). A mesotesta é parenquimática, proliferando na região sub-hilar apresentando numerosos idioblastos fenólicos (figuras 14-15). Não se encontram resíduos de células do tegumento interno, as quais foram completamente reabsorvidas. Observa-se a ocorrência de grande quantidade de tecido endospérmico (figuras 14-15) e pequeno crescimento do embrião, o qual se mantém ligado ao suspensor (figura 15).

Estádio V (figuras 16-18) - Fase caracterizada pelo alongamento celular em toda a semente, e especialmente, pelo crescimento do embrião. O pericarpo não exibe alterações, mas, devido ao crescimento do embrião, há compressão do endocarpo interno que delimita a cavidade seminal.

A testa tem sua estrutura definida nessa fase, apresentando-se delgada em sua maior extensão. É formada pela epiderme externa (exotesta) fenólica e paliçádica (figuras 17-18). O mesofilo da testa (mesotesta) apresenta-se parenquimático e a epiderme interna (endotesta) fica comprimida, justaposta a resíduos do nucelo. Na região da rafe, há um aumento na espessura tegumentar, devido à presença do feixe vascular (figura 17), que termina seu trajeto na calaza, mantendo a anti-rafe com pequena espessura (figura 18). Na região do hilo e lobo radicular, o tegumento é bem mais espesso que no restante da semente, devido à ocorrência de dupla camada paliçádica na exotesta e ao grande número de camadas parenquimáticas sub-hilares (figura 16). Nessa região, observam-se dois nítidos blocos de idioblastos fenólicos, dispostos lateralmente à região em que irá se diferenciar a barra de traqueídes.

A semente permanece ligada ao pericarpo pelo funículo, cuja estrutura está preenchida, em sua maior parte, pelo feixe vascular que irriga a semente.

O endosperma ainda continua sendo consumido e, ao final dessa fase, será exaurido.

Estádio VI (figuras 19-30) - Neste estádio, ocorre o final da maturação do fruto e da semente. O fruto é uma sâmara achatada, de ala circular dorso-ventral, basal e apical (figura 21). Apresenta coloração castanho-parda e o pericarpo completamente seco. Exibe intensa vascularização, distinta morfologicamente, mais evidente sobre o núcleo seminífero que sobre a ala. Ocorre uma (mais freqüentemente) ou duas sementes, estas isoladas em cavidades monospérmicas.

O exocarpo do fruto maduro é unisseriado, composto de células cubóides revestidas por fina cutícula (figuras 25, 27, 29-30). Os tricomas ainda persistentes não modificam sua estrutura inicial (figura 25, 29-30).

No mesocarpo do núcleo seminífero e da ala, os idioblastos secretores da camada subepidérmica são comprimidos, e seu conteúdo torna-se pouco evidente (figuras 25, 27, 29-30). As células parenquimáticas do mesocarpo na região periférica tornam-se também comprimidas (figuras 29-30). Em todo o restante do mesocarpo, as células continuam volumosas e, eventualmente, apresentam pequenos cristais de oxalato de cálcio em seu interior. Os idioblastos secretores fundem-se, formando canais longos e irregulares, imersos no mesocarpo (figura 27). Também inseridos nessa região, observam-se alguns idioblastos mucilaginosos de grande tamanho. Os feixes laterais são do tipo colateral aberto, com presença de câmbio ativo em vários deles. Há também grande quantidade de fibras bem lignificadas, acompanhando cada feixe vascular. Devido à maturação do fruto, lignificação do endocarpo externo e diferença de textura das células, ocorre o desprendimento do mesocarpo, que estava aderido ao endocarpo lenhoso, formando um espaço entre os dois tecidos (figura 27-29).

O endocarpo externo fibroso encontra-se completamente lignificado. O endocarpo interno mantém-se bem frouxo, com células braciformes e algumas de conteúdo fenólico. Ao redor da semente, ocorre compressão de parte desse tecido. Na região da ala, o endocarpo interno não se diferencia (figuras 29-30).

A parte basal do fruto desenvolve um câmbio vascular, que produz certa quantidade de xilema e floema secundários, este último em menor escala.

A semente (figuras 19-20, 22-24) tem tegumento marrom escuro, é campilótropa como o óvulo, tem o hilo bem evidente e de formato circular (figura 22). A partir do hilo, pode-se observar a rafe (figura 22), de pigmentação mais intensa que o restante do tegumento. A semente possui lobo radicular muito evidente (figura 22), sobre o qual se dispõe a micrópila. Ao final da maturação, apenas a camada paliçádica fenólica da testa é distinta (figura 20). Além dos compostos fenólicos, essa camada também acumula lipídios e alcalóides. Como são sementes exalbuminosas, nessa fase o embrião constitui a amêndoa (figura 19). O embrião é sempre único e possui eixo hipocótilo-radídula curvo, ligado a dois cotilédones carnosos e pouco espessos (figuras 23-24), de estrutura usual, com protoderme, meristema fundamental e procâmbio (figura 19). Suas células são ricas em grãos de amido. Ao final da maturação, ocorrem espessamentos de natureza péctica nas paredes de algumas células dos cotilédones, dispostos irregularmente entre grupos de células parenquimáticas. O eixo embrionário apresenta nítida região hipocótilo-radicular, nó cotiledonar lateralmente formado e plúmula pouco diferenciada (figuras 19,24). 

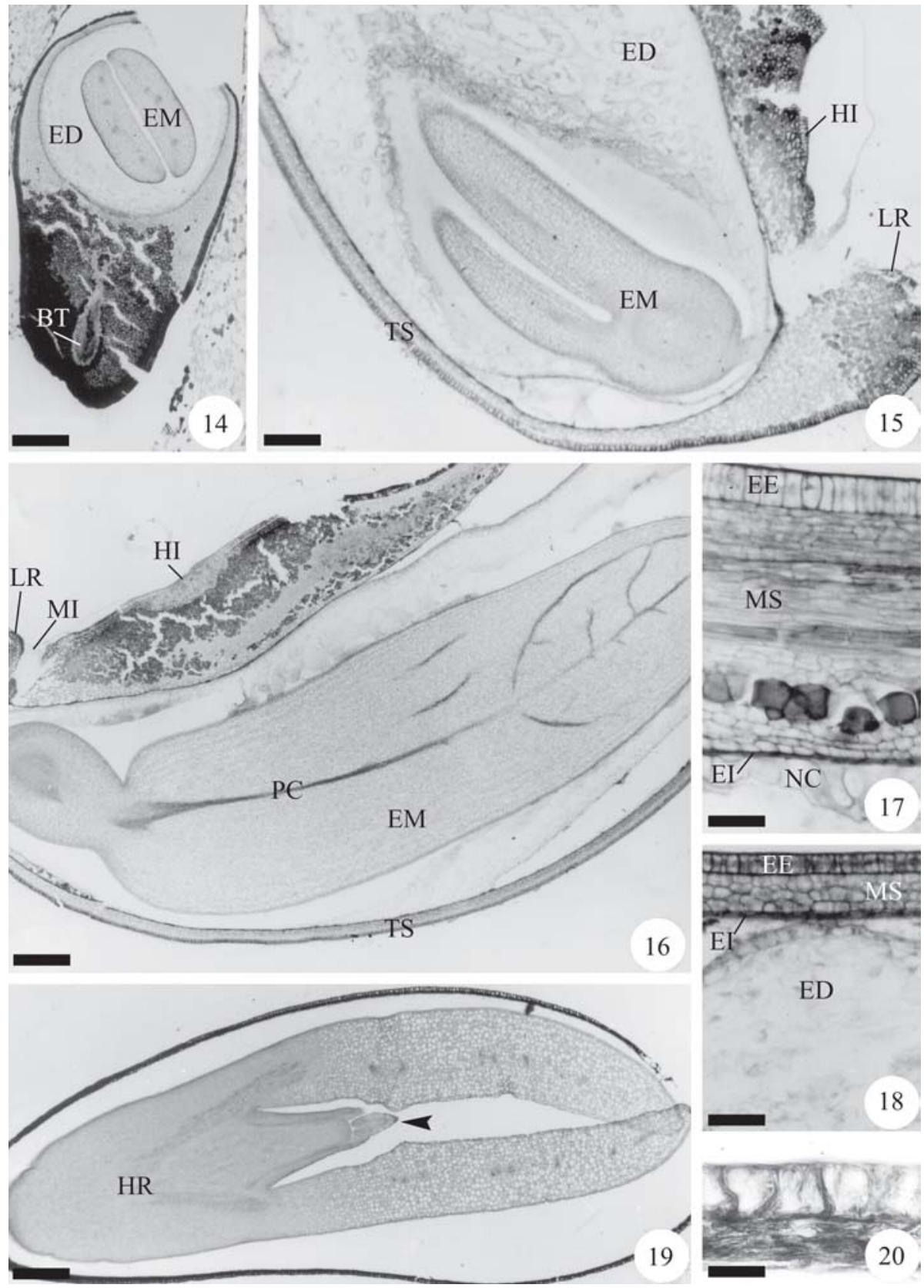

Figuras 14-20. Semente de Pterocarpus violaceus. Seções longitudinais, exceto 14 e 19 que são transversais. 14-15. Estádio IV. Semente jovem em desenvolvimento. 16-18. Estádio V. 16. Vista geral da semente; notar grande alongamento dos cotilédones, com nítidos cordões procambiais. 17-18. Detalhe da semente na região da rafe e anti-rafe, respectivamente, com resíduos do tecido nucelar e endosperma. 19-20. Estádio VI. 19. Semente madura em vista geral, mostrando o eixo embrionário (ponta de seta indica plúmula). 20. Detalhe da testa com mesofilo e epiderme interna comprimidos. (BT = barra de traqueídes; $\mathrm{ED}=$ endosperma; $\mathrm{EE}$ = epiderme externa; $\mathrm{EI}=$ epiderme interna; $\mathrm{EM}$ = embrião; $\mathrm{HI}$ = hilo; $\mathrm{HR}=$ eixo hipocótilo-radícula; $\mathrm{LR}$ = lobo radicular; $\mathrm{MI}$ = micrópila; $\mathrm{MS}=$ mesofilo; $\mathrm{NC}=$ nucelo; $\mathrm{PC}=$ procâmbio; $\mathrm{TS}$ = testa). $\mathrm{Barra}=400 \mu \mathrm{m}(14,16,19), 200 \mu \mathrm{m}(15), 50 \mu \mathrm{m}(17-18,20)$.

Figures 14-20. Pterocarpus violaceus seed. LS (14 and 19, TS). 14-15. Stage IV. Young seed. 16-18. Stage V. 16. General view of the seed; note the cotyledon enlongation, with evident procambial strands. 17-18. Detail of the raphe and the anti-raphe region, respectively, with nucellus and endosperm. 19-20. Stage VI. 19. Mature seed in general view showing the embryo axis (arrowhead indicates plumule). 20. Detail of the testa with the mesophyll and the inner epidermis compressed. (BT $=$ tracheid-bar; $\mathrm{ED}=$ endosperm; $\mathrm{EE}=$ outer epidermis; $\mathrm{EI}=$ inner epidermis; $\mathrm{EM}=$ embryo; $\mathrm{HI}=$ hilum; $\mathrm{HR}=$ embryo axis; $\mathrm{LR}=$ radicular lobe; $\mathrm{MI}=$ micropile; $\mathrm{MS}=$ mesophyll; $\mathrm{NC}=$ nucellus; $\mathrm{PC}=$ procambium; $\mathrm{TS}=$ testa $) . \mathrm{Bar}=400 \mu \mathrm{m}(14,16,19), 200 \mu \mathrm{m}(15), 50 \mu \mathrm{m}$ $(17-18,20)$. 

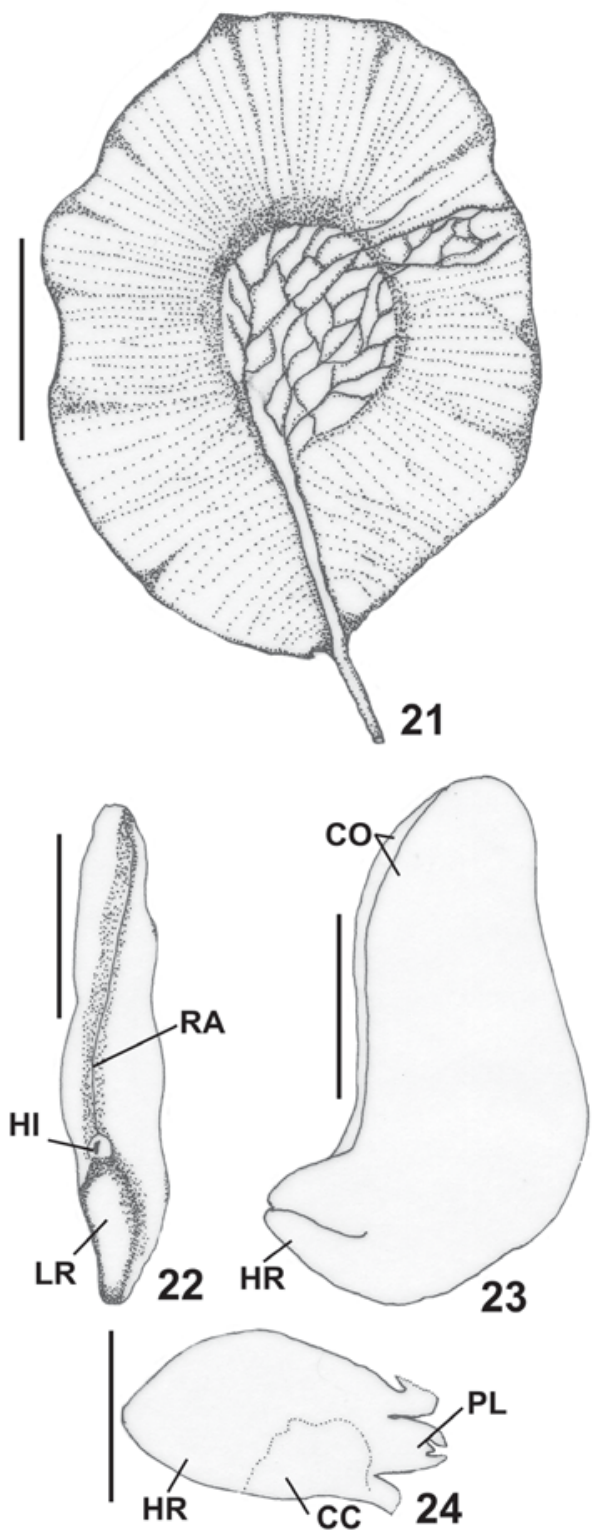

Figuras 21-24. Pterocarpus violaceus. Estádio VI (fruto e semente maduros). 21. Aspecto geral do fruto maduro. 22. Vista frontal da semente, exibindo a região rafeal, hilo e lobo radicular. 23. Vista lateral do embrião com os dois cotilédones e o eixo hipocótilo-radícula curvo. 24. Detalhe do eixo embrionário. $(\mathrm{CC}=$ cicatriz cotiledonar, $\mathrm{CO}=$ cotilédone; $\mathrm{HI}=$ hilo $; \mathrm{HR}=$ eixo hipocótilo-radícula; $\mathrm{LR}=$ lobo radicular; $\mathrm{PL}=$ plúmula; $\mathrm{RA}=$ rafe $)$. $\mathrm{Barra}=2 \mathrm{~cm}$ (21), $5 \mathrm{~mm}$ (22-23), $2 \mathrm{~mm}$ (24).

Figures 21-24. Pterocarpus violaceus. Stage VI (mature fruit and seed). 21. General aspect of the mature fruit. 22. Seed in frontal view showing the rafeal region, the hilum and the radicular lobe. 23. Embryo lateral view with two cotyledons and the embryo axis. 24. Detail of the embryo axis. $(\mathrm{CC}=$ cotyledon scar, $\mathrm{CO}=$ cotyledon; $\mathrm{HI}=$ hilum; $\mathrm{HR}=$ embryo axis; $\mathrm{LR}=$ radicular lobe; $\mathrm{PL}=$ plumule; $\mathrm{RA}=$ raphe). $\mathrm{Bar}=2 \mathrm{~cm}(21), 5 \mathrm{~mm}(22-23), 2 \mathrm{~mm}(24)$.

\section{Discussão}

O fruto de $P$. violaceus foi classificado como sâmara por Barroso et al. (1999), embora Dudik (1981) tenha proposto a utilização do termo legume para todos os frutos de leguminosas. Lima (1989-1990) descreveu frutos de Pterocarpus Jacq. como sâmaras de forma suborbicular, com posição circular da ala, de venação reticulada, apresentando falsos septos, de núcleo seminífero distinto e sem apêndices ou espinhos. Essa descrição confere com o observado em $P$. violaceus Vogel, que apresenta a estrutura típica do gênero.

Augspurger (1986) relacionou a morfologia dos frutos alados à dispersão e classificou Pterocarpus rohrii Vahl, espécie de grande semelhança carpológica com $P$. violaceus, como um tipo aerodinâmico chamado "undulator", nome dado em função de seu mecanismo de dispersão.

A presença de falsos septos, como os que formam câmaras monospérmicas no fruto de Pterocarpus, tem sido utilizada para caracterizar um grupo de gêneros da tribo Dalbergieae (Polhill 1981a) e também para distinguir Pterocarpus dos demais gêneros que produzem sâmaras suborbiculares (Lima 1989-1990). As subdivisões aqui observadas no fruto de $P$. violaceus, que constituem as cavidades monospérmicas, foram consideradas como falsos septos, já que as mesmas não existiam pré-formadas no ovário (vide a figura 2), sendo produzidas a partir do estádio II (como registrado na figura 6).

Dudik (1981) apresentou uma lista de características que refletem o grau de especialização de frutos e sementes de espécies de leguminosas. Várias delas ocorrem em $P$. violaceus, como a presença de frutos monospérmicos, indeiscentes e septados transversalmente. Com relação à estrutura seminal, o referido autor considerou derivadas, entre outras, a campilotropia e a ausência de endosperma na maturidade, de alas ou de arilos; todos esses aspectos também foram observados na espécie estudada.

Como freqüentemente ocorre em frutos indeiscentes, as sementes de Dalbergieae são muito homogêneas, não fornecendo subsídios importantes à sistemática do grupo. Sua posição em relação ao eixo do fruto e a presença das cavidades monospérmicas mostram, porém, as afinidades entre os gêneros Pterocarpus, Paramachaerium Ducke, Centrolobium Mart. ex Benth. e Tipuana (Benth.) Benth. (Lima 1989-1990).

De acordo com a classificação de Martin (1946), a semente de P. violaceus possui embrião total, de 


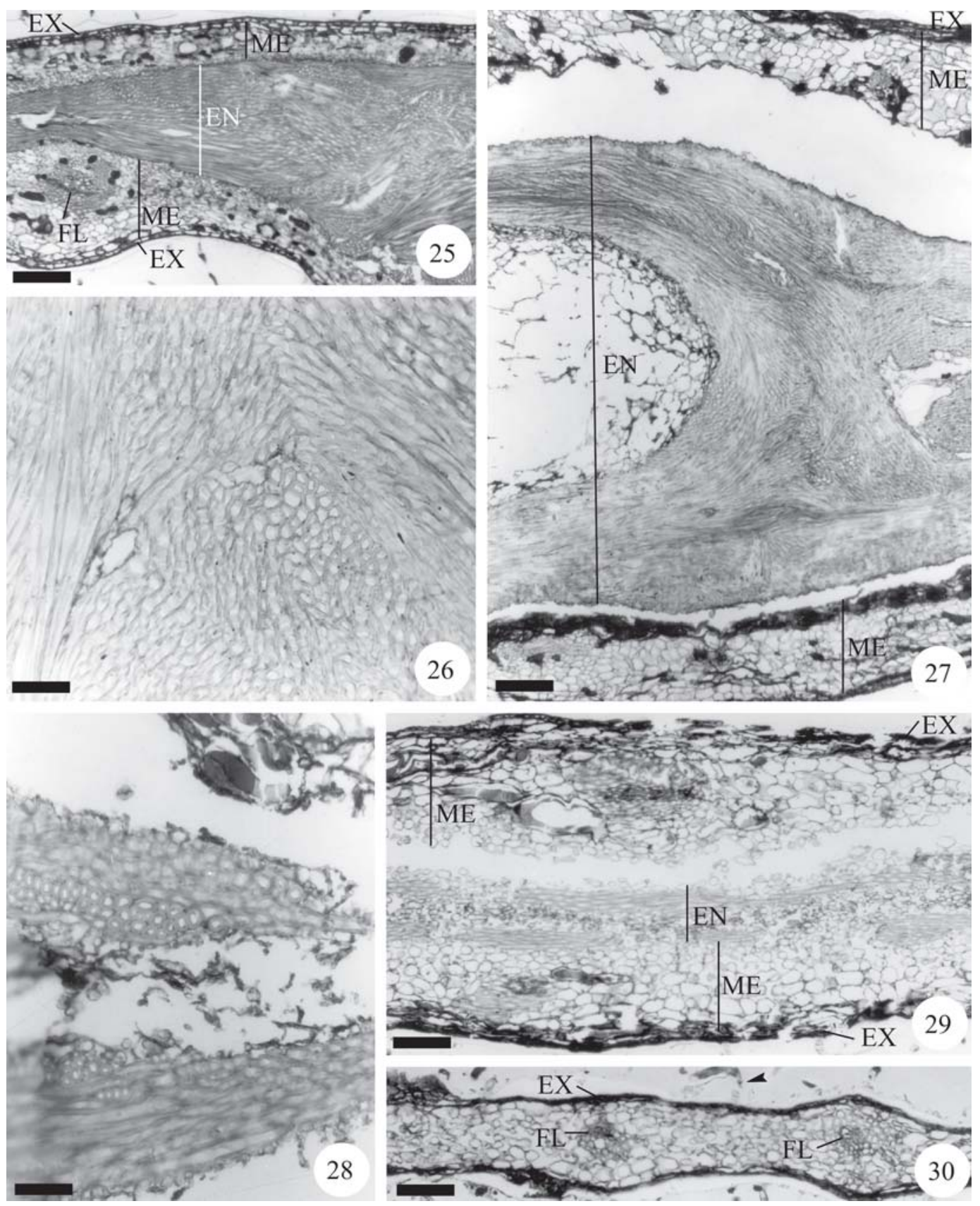

Figuras 25-30. Estádio IV. Pericarpo maduro de Pterocarpus violaceus. Seções transversais, exceto 30, que é longitudinal. 25. Vista geral da região de transição entre ala-núcleo seminífero. 26. Detalhe do endocarpo externo fibroso, com células em posição oblíqua, longitudinal e transversal. 27. Detalhe do núcleo seminífero, evidenciando o exocarpo e mesocarpo com células comprimidas, desprendidas do endocarpo fibroso. 28. Endocarpo externo fibroso e interno com células parenquimáticas braciformes. 29. Detalhe da ala mostrando o exocarpo, mesocarpo e endocarpo fibroso. 30. Região periférica da ala evidenciando exocarpo e mesocarpo comprimidos, alguns tricomas (ponta de seta) e feixes laterais. $(\mathrm{EN}=$ endocarpo; $\mathrm{EX}=$ exocarpo; $\mathrm{FL}=$ feixe lateral; $\mathrm{ME}=$ mesocarpo $).$ Barra $=200 \mu \mathrm{m}(25,27), 50 \mu \mathrm{m}(26,28), 100 \mu \mathrm{m}(29,30)$.

Figures 25-30. Stage IV. Pterocarpus violaceus mature pericarp. TS (30, LS). 25. General view of the region between the wing and seed chamber. 26. Detail of the outer fibrous endocarp. 27. Detail of the seed chamber, showing the compressed cells of the exocarp and mesocarp separeted from the fibrous endocarp. 28. Outer endocarp formed by sclerified cells and inner endocarp with armed parenchymatous cells. 29. Detail of the seed wing showing the exocarp, mesocarp and the fibrous endocarp. 30. Wing region with compressed exocarp and mesocarp, some trichomes (arrowhead) and lateral bundles. (EN = endocarp; $\mathrm{EX}=$ exocarp; $\mathrm{FL}=$ lateral bundle; $\mathrm{ME}=$ mesocarp). $\mathrm{Bar}=200 \mu \mathrm{m}(25,27), 50 \mu \mathrm{m}(26,28), 100 \mu \mathrm{m}(29,30)$. 
posição axial na semente e do tipo "investing". Na nomenclatura adotada por Barroso et al. (1999), o embrião também é dito axial, de formato invaginado, do subtipo papilionáceo.

Anatomicamente, o fruto de $P$. violaceus possui um único estrato fibroso lignificado no endocarpo externo, com disposição irregular de fibras, muito semelhante ao observado em Tipuana tipu (Benth.) Kuntze por Martins \& Oliveira (2001). A presença desse estrato único e contínuo ao redor da semente leva à indeiscência do fruto, caráter apomórfico segundo Fahn \& Zohary (1955). Segundo esses autores, existem numerosos legumes que apresentam duas camadas no estrato esclerenquimático, sendo estes considerados plesiomórficos.

Com relação à vascularização, nas espécies monocarpelares, a presença de três traços vasculares (um dorsal e dois ventrais) é um caráter ancestral, sendo a redução do número de traços carpelares considerada derivada (Puri 1951). Na espécie estudada, verificou-se a fusão filogenética dos feixes ventrais, de modo que, com relação a esse critério, $P$. violaceus pode ser considerada como filogeneticamente mais avançada que Tipuana tipu (Martins \& Oliveira 2001) e Centrolobium tomentosum Guill. ex Benth. (D.M.T. Oliveira et al., dados não publicados), outras espécies da tribo Dalbergieae.

Tradicionalmente, o desenvolvimento de frutos e sementes é analisado dividindo-se o processo em estádios, iniciativa que começou com estudos de frutos carnosos, especialmente os drupáceos (Lilleland 1930, 1932, 1933, Tukey \& Young 1939, Nitsch 1953). Os autores desses trabalhos descreveram três períodos de crescimento, assim caracterizados: no período I, ocorre rápido aumento no tamanho do fruto e tegumentos seminais; no período II, o embrião diferencia-se, embora a velocidade de crescimento do fruto diminua sensivelmente; e o período III é caracterizado pela paralisação do desenvolvimento do embrião e retomada de um ativo alongamento no fruto.

No caso de $P$. violaceus, foram observados seis estádios de desenvolvimento, de modo semelhante ao descrito por Oliveira \& Beltrati (1993) para frutos de Inga fagifolia Willd. ex Benth. (Mimosoideae). O enquadramento do desenvolvimento nos seis estádios ocorreu porque a diferenciação do pericarpo e da semente não são concomitantes, tanto em Pterocarpus quanto em Inga Mill. Nessas espécies, o pericarpo tem sua fase de maturação no estádio IV, numa fase muito adiantada em relação ao amadurecimento da semente (estádio VI).
Quanto ao desenvolvimento seminal, Souza (1984, 1993) e Oliveira \& Beltrati (1993) relataram dois diferentes processos: os dois primeiros trabalhos referem-se, respectivamente, ao estudo dos frutos de Lonchocarpus muehlbergianus Hassl. (Faboideae) e de Acacia paniculata Willd. (Mimosoideae), em que o desenvolvimento da semente ocorre paralelamente ao do pericarpo. Tal fato também foi verificado em Tipuana tipu (Martins \& Oliveira 2001) e Centrolobium tomentosum (D.M.T. Oliveira et al., dados não publicados), ambas espécies de Faboideae. No presente trabalho e no estudo de Oliveira \& Beltrati (1993), observou-se que a diferenciação seminal ocorre somente após a lignificação pericárpica. Segundo Roth (1977), nos frutos que desenvolvem prematuramente tecidos lignificados, forma-se também um tecido multisseriado que reveste a cavidade seminal, o "seed cushion", cuja função é amortecer a pressão que o pericarpo em maturação exerce sobre a semente ainda jovem. Assim, quando os tecidos esclerenquimáticos do meso e/ou endocarpo e o parênquima que reveste a cavidade seminal se formam em fase adiantada do amadurecimento, a semente só se diferencia após essa fase, dados que conferem com o aqui observado.

Eames \& MacDaniels (1953) generalizaram a ocorrência da absorção completa do tegumento interno e do nucelo durante o desenvolvimento das sementes de leguminosas. Em P. violaceus, verifica-se que ocorre compressão do tegumento interno, seguida da sua absorção, conferindo com o padrão da família.

A presença de grande densidade de tricomas do ovário está relacionada à defesa da planta, especialmente contra insetos fitófagos, além de poder complementar a defesa química do vegetal, produzida pela formação e exudação de terpenos, fenóis, alcalóides e outras substâncias, que agem como repelentes pelo gosto e/ou pelo cheiro desagradável (Theobald et al. 1979). Em P. violaceus, essa grande densidade foi observada exclusivamente no ovário, já que, durante a ontogênese, houve apenas a formação de novas células epidérmicas comuns, também ocorrendo diminuição no número absoluto de tricomas devido à abscisão.

Outro aspecto que merece destaque é a ocorrência de inúmeros idioblastos fenólicos, tanto no ovário como no pericarpo maduro e na testa da semente. Segundo Suárez \& Engleman (1980), esta ocorrência é relacionada à proteção do embrião contra patógenos. De modo geral, embora as funções dos compostos fenólicos não sejam claramente conhecidas, eles parecem atuar na proteção contra herbívoros, especialmente insetos, e também contra fungos e 
bactérias (Swain 1979), além de conferirem coloração típica e de aumentarem a dureza dos tegumentos seminais (Boesewinkel \& Bouman 1984).

Uma característica típica de sementes retidas em pericarpos lenhosos e indeiscentes é a transferência da função de proteção realizada pelos tegumentos para o pericarpo, com a consequiente redução estrutural dos envoltórios seminais. Como já descrito em Tipuana tipu (Martins \& Oliveira 2001) e observado em Centrolobium tomentosum (Oliveira et al., dados não publicados), também na semente de $P$. violaceus o tegumento é delgado e pouco diferenciado, mostrando apenas uma leve tendência à estrutura exotestal freqüentemente marcante nas leguminosas (Boesewinkel \& Bouman 1984). Esse tipo de tegumento não diferenciado, segundo os referidos autores, ocorre em famílias avançadas com frutos indeiscentes, por exemplo os drupáceos. O papel de proteção do tegumento, portanto, é transferido para o pericarpo na região do núcleo seminífero, que possui intensa lignificação e grande quantidade de compostos fenólicos. Embora o tegumento não tenha a estrutura característica das leguminosas, a semente de $P$. violaceus exibe alguns aspectos hilares típicos das Faboideae (Corner 1951), como o tamanho avantajado, com barra de traqueídes na região sub-hilar, onde a mesotesta tem maior número de camadas, e exotesta com dupla camada paliçádica.

Com relação à poliembrionia, pode-se afirmar que o processo é relatado para várias espécies da família Fabaceae, sendo referido por Oliveira \& Beltrati (1994) para Inga fagifolia e por Villari (1990-1991) e Martins \& Oliveira (2001) para Tipuana tipu. Em P. violaceus, contudo, apesar do grande número de sementes analisadas, não foram encontradas sementes poliembriônicas. Como não foi encontrado nenhum estudo detalhado sobre a poliembrionia no grupo analisado, torna-se difícil especular a esse respeito. Estudos embriológicos e envolvendo maior número de espécies são necessários para poder esclarecer esse processo.

\section{Referências bibliográficas}

AUGSPURGER, C.K. 1986. Morphology and dispersal potential of wind-dispersed diaspores of neotropical trees. American Journal of Botany 73:353-363.

BARROSO, G.M., MORIM, M.P., PEIXOTO, A.L. \& ICHASO, C.L.F. 1999. Frutos e sementes: morfologia aplicada à sistemática de dicotiledôneas. Editora UFV, Viçosa.

BOESEWINKEL, F.D. \& BOUMAN, F. 1984. The seed: structure. In Embryology of Angiosperms. (B.M. Johri, ed.). Springer-Verlag, Berlin, p.567-610.
CORNER, E.J.H. 1951. The leguminous seed. Phytomorphology 1:117-150.

DUDIK, N.M. 1981. Morphology of the pods of Leguminales (Fabales). In Advances in legume systematics. Part 2 (R.M. Polhill \& P.H. Raven, eds.). Royal Botanic Gardens, Kew, p.897-901.

EAMES, A.J. \& MACDANIELS, L.H. 1953. An introduction to plant anatomy. $3^{\text {rd }}$ ed. Tata McGraw-Hill Publishing, New Delhi.

FAHN, A. \& ZOHARY, M. 1955. On the pericarpial structure of the legumen, its evolution and relation to dehiscence. Phytomorphology 5:99-111.

GUNN, C.R. 1984. Fruits and seeds of genera in the subfamily Mimosoideae (Fabaceae). Technical Bulletin 1681:1-194.

JENSEN, W.A. 1962. Botanical histochemistry: principles and pratice. W.H. Freeman, San Francisco.

JOHANSEN, D.A. 1940. Plant microtechnique. McGraw-Hill Book, New York.

KARNOVSKY, M.J. 1965. A formaldehyde-glutaraldehyde fixative of high osmolality for use in electron microscopy. Journal of Cell Biology 27:137A-138A.

LILLELAND, O. 1930. Growth study of the apricot fruit. Proceeding of the American Society for Horticultural Science 29:237-245.

LILLELAND, O. 1932. Growth study of the peach fruit. Proceeding of the American Society for Horticultural Science 29:8-12.

LILLELAND, O. 1933. Growth study of the plum fruit - I. The growth and changes in chemical composition of the climax plum. Proceeding of the American Society for Horticultural Science 30:203-208.

LIMA, H.C. 1989-1990. Tribo Dalbergieae (Leguminosae Papilionoideae) - morfologia dos frutos, sementes e plântulas e sua aplicação na sistemática. Arquivos do Jardim Botânico do Rio de Janeiro 30:1-42.

LORENZI, H. 1992. Árvores brasileiras: manual de identificação e cultivo de plantas arbóreas nativas do Brasil. Plantarum, Nova Odessa, p.168.

MARTIN, A.C. 1946. The comparative internal morphology of seeds. The American Midland Naturalist 36:513-660.

MARTINS, M.A.G. \& OLIVEIRA, D.M.T. 2001. Morfoanatomia e ontogênese do fruto e semente de Tipuana tipu (Benth.) O. Kuntze (Fabaceae: Faboideae). Revista Brasileira de Botânica 24: 109-121.

NITSCH, J.P. 1953. The physiology of fruit growth. Annual Review of Plant Physiology 4:199-236.

O'BRIEN, T.P., FEDER, N. \& McCULLY, M.E. 1964. Polychromatic staining of plant cell walls by toluidine blue O. Protoplasma 59:368-373.

OLIVEIRA, D.M.T. \& BELTRATI, C.M. 1993. Aspectos anatômicos dos frutos e sementes em desenvolvimento de Inga fagifolia (Fabaceae: Mimosoideae). Revista Brasileira de Biologia 53:625-636.

OLIVEIRA, D.M.T. \& BELTRATI, C.M. 1994. Morfologia e anatomia dos frutos e sementes de Inga fagifolia Willd. (Fabaceae: Mimosoideae). Revista Brasileira de Biologia 54:91-100. 
POLHILL, R.M. 1981a. Dalbergieae. In Advances in legume systematics. Part 1 (R.M. Polhill \& P.H. Raven, eds.). Royal Botanic Gardens, Kew, p.233-242.

POLHILL, R.M. 1981b. Papilionoideae. In Advances in legume systematics. Part 1 (R.M. Polhill \& P.H. Raven, eds.). Royal Botanic Gardens, Kew, p.191-204.

POLHILL, R.M, RAVEN, P.H. \& STIRTON, C.H. 1981. Evolution and systematics of the Leguminosae. In Advances in legume systematics. Part 1 (R.M. Polhill \& P.H. Raven, eds.). Royal Botanic Gardens, Kew, p.1-26.

PURI, V. 1951. The role of floral anatomy in the solution of morphological problems. The Botanical Review 17:471-553.

RAVEN, P.H. \& POLHILL, R.M. 1981. Biogeography of the Leguminosae. In Advances in legume systematics. Part 1 (R.M. Polhill \& P.H. Raven, eds.). Royal Botanic Gardens, Kew, p.27-34.

ROTH, I. 1977. Fruits of Angiosperms. Gebrüder Borntraeger, Berlin. (Handbuch der Pflanzenanatomie).

SASS, J.E. 1951. Botanical microtechnique. 3.ed. State Press, Iowa.

SOUZA, L.A. 1984. Anatomia do desenvolvimento do pericarpo de Lonchocarpus muehlbergianus Hassler (Leguminosae - Faboideae). Revista Unimar 6:5-19.
SOUZA, L.A. 1993. Morfo-anatomia do desenvolvimento do fruto de Acacia paniculata Willd. (Leguminosae). Arquivos de Biologia e Tecnologia 36:851-871.

SUÁREZ, G.R. \& ENGLEMAN, E.M. 1980. Deposito de taninos en la testa de Amaranthus hypochondriacus L. (alegria). Agrociencia 42:35-50.

SWAIN, T. 1979. Tanins and lignins. In Herbivores: their interactions with secondary plant metabolites (G.A. Rosenthal \& D.H. Janzen, ed.). Academic Press, New York, p.657-682.

THEOBALD, W.L., KRAHULIK, J.L. \& ROLLINS, R.C. 1979. Trichomes description and classification. In Anatomy of the Dicotyledons. v.1 (R.C. Metcalfe \& L. Chalk, eds.). Claredon Press, Oxford, p.40-53.

TUKEY, H.B., YOUNG, J.O. 1939. Histological study of the developing fruit of the sour cherry. Botanical Gazette 100:723-749.

VILLARI, R. 1990-1991. Embryological observations on Tipuana tipu (Benth.) O. Kuntze (Dalbergieae, Papilionaceae). Giornale Botanico Italiano 124:293-300.

VON TEICHMAN, I. \& VAN WYK, A.E. 1991. Trends in the evolution of dicotyledonous seeds based on character associations, with special reference to pachychalazy and recalcitrance. Botanical Journal of the Linnean Society 105:211-237. 